\title{
Direct-Write Fabrication of $\mathrm{Pb}(\mathrm{Nb}, \mathrm{Zr}, \mathrm{Ti}) \mathrm{O}_{3}$ Devices: Influence of Paste Rheology on Print Morphology and Component Properties
}

\author{
Sherry L. Morissette ${ }^{\star \dagger}$ and Jennifer A. Lewis* \\ Department of Materials Science and Engineering, University of Illinois, Urbana, Illinois 61801 \\ Paul G. Clem, ${ }^{*}$ Joseph Cesarano III, ${ }^{*}$ and Duane B. Dimos* \\ Sandia National Laboratories, Albuquerque, New Mexico 87185
}

\begin{abstract}
Lead niobium zirconate titanate (PNZT) pastes with tailored rheological properties have been developed for direct-write fabrication of thick-film capacitor elements in highly integrated, multifunctional electroceramic devices. Such pastes exhibited pseudoplastic behavior with a low shear apparent viscosity of roughly $1 \times 10^{6} \mathrm{cP}$. On aging, the degree of shear thinning and the low shear apparent viscosity decreased. Pastes prepared from as-received powders attained printable, steady-state viscosities of $\sim 2 \times 10^{5} \mathrm{cP}$ after 50 days of aging. In contrast, pastes prepared from dispersant-coated powders showed no measurable rheological changes after 1 day of aging. Square elements were patterned on dense alumina substrates or Teflon sheets. Leveling behavior as a function of time for single line prints, and the resulting surface topographies of dried PNZT films were measured by laser profilometry. PNZT layers sintered at varying temperatures between $950^{\circ}$ and $1050^{\circ} \mathrm{C}$ for $5 \mathrm{~h}$ in either air or a lead-rich atmosphere yielded porous microstructures as revealed by scanning electron microscopy (SEM). Such layers exhibited dielectric constants $(K)$ of $1400-1570$ at $1 \mathrm{kHz}$ with dissipation factors $(D)$ of less than $4.1 \%$.
\end{abstract}

\section{Introduction}

$\mathrm{F}^{\mathrm{a}}$ BRICATION of advanced electrical ceramic devices is commonly achieved via a multilayer build sequence that utilizes thick film process technologies such as tape casting and screenprinting. ${ }^{1-8}$ As device complexity increases, the need for alternate fabrication methods which offer a simple and rapid means of integrating multiple materials in three-dimensional architectures is required. Currently, solid free-form fabrication (SFF) techniques are receiving considerable attention. Direct-write fabrication, an emerging SFF method, utilizes a micropen technique to produce integrated multifunctional, multimaterial electroceramic devices in a rapid, simplistic way. ${ }^{9,10}$ In this method, a thin cylindrical extrudate (minimum diameter $\approx 25 \mu \mathrm{m}$ ) is deposited in a precise pattern onto a substrate via computer-aided design (CAD) instruction. Complex, three-dimensional architectures can be constructed in a layer-by-layer build sequence from individual layers containing multiple materials. Although drying of as-printed layers is

\section{S. E. Trolier-McKinstry-contributing editor}

\footnotetext{
Manuscript No. 188921. Received November 29, 1999; approved May 7, 2001.
This research was supported by the National Science Foundation under Grant No. DMR94-53446 and by the U.S. Department of Energy under Contract DE-AC0494AL8500. Sandia is a multiprogram laboratory operated by Sandia Corp., a Lockheed Martin Co., for the U.S. Department of Energy.

${ }^{*}$ Member, American Ceramic Society.

Now at the Materials Processing Center, Massachusetts Institute of Technology, Cambridge, Massachusetts 02139 .
}

required before deposition of additional layers, this direct-write approach yields significant advantages over the conventional method for producing multilayer devices, such as those based on lamination of tape-cast layers with screen-printed elements, including the ability to modify patterned designs on-line during printing and to incorporate multiple materials in individual layers.

The rheological requirements of thick film pastes for micropen printing and screen printing are nearly identical. ${ }^{7-9,11-17}$ Hence, commercially available screen printing pastes (e.g., silver-palladium conductor, ruthenium oxide resistor, and dielectric pastes) can be readily utilized in this direct-write approach. There is, however, a need to develop rheologically tailored, cofireable thick film pastes of functional ceramic materials (e.g., lead niobium zirconate titanate (PNZT), zinc oxide $(\mathrm{ZnO})$, etc.). ${ }^{18-20}$ Such pastes offer one the ability to fabricate fully integrated devices containing high-performance PNZT capacitor and/or ZnO varistor elements.

The influence of paste rheology on line resolution and surface topography of as-deposited elements has been investigated previously for micropen printing ${ }^{9,11}$ and related screen printing systems. ${ }^{14,16,17,21,22}$ Dimos et al. ${ }^{9,11}$ studied the relation between the rheological behavior and print properties of a series of commercially available thick film pastes patterned using a micropen apparatus. These studies showed that the commercially available thick film pastes exhibited shear thinning behavior with apparent viscosities of $\sim 1 \times 10^{5} \mathrm{cP}$ in the printing range $\left(\dot{\gamma}=20-85 \mathrm{~s}^{-1}\right)$; however, significant differences in their rheological behavior were observed in the low-shear $\left(\dot{\gamma}<1 \mathrm{~s}^{-1}\right)$ or settling regime. Such differences resulted in markedly different line resolution and surface topographies. For example, conductor pastes which exhibited high viscosity at low shear yielded high definition patterns, whereas the lower-viscosity resistor pastes produced lowdefinition traces with smooth surface topographies. ${ }^{9,11}$ Clearly, the low shear rheological behavior of thick film pastes dictates the settling behavior and, hence, the resulting line resolution and surface topographies of printed features.

We have developed PNZT thick film pastes with tailored rheological properties for micropen fabrication of capacitor elements. In this paper, we describe the protocol utilized to produce these PNZT pastes, and the resulting properties of printed capacitor devices. $\mathrm{ZnO}$ pastes prepared via this protocol and the properties of $\mathrm{ZnO}$ printed components will be presented in a companion paper. ${ }^{23}$ In this study, we first examined the influence of dispersant and vehicle composition on the respective rheological behavior of PNZT suspensions and ethyl cellulose solutions. These results served as a benchmark for the design of subsequent paste formulations. Smooth surface topographies which are necessary to achieve uniform dielectric thickness in printed capacitor devices were achieved by optimization of paste rheology via compositional tailoring; i.e., the rheological behavior of PNZT pastes mimicked that of the commercial resistor paste described above. Stress viscometry measurements of representative PNZT pastes (volume fraction PNZT $\left(\phi_{\mathrm{PNZT}}\right)=0.35$ ) prepared from 
as-received and dispersant-coated powders revealed that aging phenomena in such systems are related to dispersant adsorption kinetics. Laser profilometry, which was used to assess the surface topography of as-deposited layers, showed that printed layers had smooth surface topography and thus uniform thickness. Finally, the microstructure and electrical properties of sintered capacitor devices were evaluated.

\section{Experimental Procedure}

\section{(1) Materials System}

Lead zirconate niobium titanate (PNZT: $\mathrm{Pb}\left(\mathrm{Zr}_{0.52} \mathrm{Ti}_{0.48}\right)_{x^{-}}$ $\mathrm{Nb}_{1-x} \mathrm{O}_{3}$ ) powder, derived via a coprecipitation method, ${ }^{24}$ served as the ceramic phase in this study. The powder contained $6 \%$ excess lead to lower the required sintering temperature ${ }^{9,25,26}$ and, hence, improve the cofireability of multilayer electroded packages. The as-received PNZT powders exhibited a trimodal size distribution with characteristic sizes of roughly $2-5,20$, and $45-50 \mu \mathrm{m}$, as determined by particle size analysis (Coulter LS Particle Size Analyzer, Fullerton, CA). This powder had a specific surface area of $2.63 \pm 0.02 \mathrm{~m}^{2} / \mathrm{g}$, and an apparent density of $7.740 \pm 0.001$ $\mathrm{g} / \mathrm{cm}^{3}$, as measured using nitrogen gas adsorption (BET) (ASAP 2010 Chemisorption Analyzer, Micromeritics Corp., Norcross, GA) and helium pycnometry (Ultrapycnometer 1000, Quantachrome Corp., Boynton Beach, FL), respectively. On attrition milling, the specific surface area of the powder increased to $3.04 \pm$ $0.04 \mathrm{~m}^{2} / \mathrm{g}$ and a bimodal particle size distribution was observed with characteristic sizes of 1.8 and $4.5 \mu \mathrm{m}$. During the three-roll milling process, the large agglomerates in both the as-received and attrition-milled powders were reduced uniformly to an average particle size of $\sim 2.0 \pm 0.2 \mu \mathrm{m}$.

$\alpha$-Terpineol (boiling point $\cong 220^{\circ} \mathrm{C}$ ) (Aldrich Chemical Co., Milwaukee, WI) served as the low-volatility solvent. Four deflocculants were evaluated for dispersing the PNZT powder in $\alpha$-terpineol: (1) a polyenoic acid (Menhaden fish oil (MFO), R. E. Mistler, Inc., Morrisville, PA), (2) a phosphate ester (Emphos21A, Witco Corp., Greenwich, CT), (3) a fatty acid (oleic acid, Aldrich Chemical Co.), and (4) a fatty acid ester (Hypermer PS-3, ICI America, Washington, DC). Ethyl cellulose (EC) (Ethocel, Standard 10, Dow Chemical Corp., Midland, MI) with a 48.0$49.5 \%$ ethoxy content, and a molecular weight of $\sim 10500$ was used as the binder phase for these pastes.

\section{(2) Sample Preparation}

Preliminary experiments were conducted to determine dispersant effectiveness, maximum packing fraction, and the effects of binder content on the rheological behavior of the ethyl cellulose/ terpineol vehicle system. PNZT suspensions $\left(\phi_{\mathrm{PNZT}}=0.10\right)$ for dispersant evaluation were prepared by adding an appropriate amount of PNZT powder to a solution of $\alpha$-terpineol containing varying amounts (0.01-3.0 wt\% relative to powder) of dispersant. Suspensions for maximum packing fraction $\left(\phi_{\mathrm{m}}\right)$ determination were prepared by adding varying amounts of PNZT powder $\left(\phi_{\text {PNZT }}=0.05-0.40\right)$ to $\alpha$-terpineol solutions containing $1.0 \mathrm{wt} \%$ dispersant based on powder mass. All suspensions were ballmilled for $12 \mathrm{~h}$ and then characterized via stress viscometry. Vehicle systems with varying ethyl cellulose volume fraction $\left(\phi_{\mathrm{EC}}^{\text {soln }}=0.002-0.05\right)$ were prepared by diluting an ethyl cellulose stock solution to the desired $\phi_{\mathrm{EC}}^{\text {soln }}$. The stock solution was made by dissolving ethyl cellulose $\left(\phi_{\mathrm{EC}}^{\mathrm{soln}} \approx 0.06\right)$ in $\alpha$-terpineol at $45^{\circ} \mathrm{C}$.

Pastes $\left(\phi_{\mathrm{PNZT}}=0.35, \phi_{\mathrm{EC}}^{\mathrm{soln}}=0.05\right)$ were prepared from either as-received or dispersant-coated, attrition-milled PNZT powder. As-received powders were combined with a $\alpha$-terpineol solution that contained $1.0 \mathrm{wt} \%$ dispersant (based on the powder mass) and an appropriate amount of ethyl cellulose stock solution. Attritionmilled powders were dispersant coated with $1.0 \mathrm{wt} \%$ dispersant (based on the powder mass) by mixing in ethanol, which was subsequently evaporated to yield the dry, dispersed powder. The dispersed powder was then combined with appropriate amounts of ethyl cellulose ${ }^{27}$ stock solution and $\alpha$-terpineol. Pastes were first mixed manually using a Teflon rod, followed by three-roll milling
(10 $\mu \mathrm{m}$ gap, 4 passes) (Charles Ross and Son Co., Hauppauge, NY). A fineness-of-grind (FOG) gauge (BKY-Gardner U.S.A., Columbia, MD) was used to determine the average agglomerate size in the as-milled pastes.

\section{(3) Rheological Measurements}

Ethyl cellulose/terpineol vehicles and PNZT suspensions and pastes were characterized using a controlled stress rheometer (Carri-med 50, Carri-med Corp. (now TA Instruments), New Castle, DE) in stress viscometry mode. The rheometer was fitted with either a double concentric cylinder (DG) or cone and plate geometry. The rheological behaviors of PNZT suspensions and ethyl cellulose/terpineol solutions were measured using a DG cell, which yielded a stress range of $1 \times 10^{-4}-1 \times 10^{1} \mathrm{~Pa}$. The higher-viscosity PNZT pastes were characterized using a cone and plate geometry (cone diameter $=2.0 \mathrm{~cm}$, cone angle $=0.5^{\circ}$ ), which yielded a stress range of $5 \times 10^{-2}-5 \times 10^{3} \mathrm{~Pa}$. The rheological behavior of as-milled pastes was characterized first, followed by a series of measurements as a function of aging time. After a representative aliquot of paste was tested initially, the remaining paste was allowed to age undisturbed under ambient conditions. Subsequent aliquots were then removed and characterized at various time intervals. The apparent viscosity of each sample was measured as a function of shear stress in ascending order. All rheological measurements were conducted at $22^{\circ} \mathrm{C}$. Given the low volatility of the solvent, no special precautions were necessary to prevent solvent evaporation during these measurements.

\section{(4) Direct Fabrication and Component Properties}

Capacitor elements were prepared via computer-aided directdeposition of PNZT pastes onto dense alumina (Coors Ceramic Co., Golden, CO) or Teflon substrates using a commercial micropen system (Ohmcraft, Inc., Pittsford, NY) fitted with a 10/8 pen tip (outer diameter $=10$ mils; inner diameter $=8$ mils). ${ }^{9,10}$ Square components $(4 \mathrm{~mm} \times 4 \mathrm{~mm})$ were fabricated using a layer-bylayer build sequence in which individual layers $(\approx 20-30 \mu \mathrm{m})$ were allowed to settle (level) for 180-300 s under ambient conditions. The surface topography of single line prints and as-dried elements were profiled as a function of leveling time using laser profilometry (Cyberscan Corba, Cyber Optics Corp., Golden Valley, MN). On leveling, the components were dried at $110^{\circ} \mathrm{C}$ under vacuum $(50.8 \mathrm{mmHg})$. Additional layers were deposited on the as-dried films as needed for a given device.

Representative free-standing and constrained PNZT films were debinded in air at $450^{\circ} \mathrm{C}$ for $3 \mathrm{~h}$ at a heating rate of $2^{\circ} \mathrm{C} / \mathrm{min}$, and subsequently sintered in air or a $\mathrm{Pb}$-rich atmosphere at varying temperatures $\left(950^{\circ}-1050^{\circ} \mathrm{C}\right)$ for $5 \mathrm{~h}^{28}$ For comparison, bulk disk-shaped samples (radius $=9.0 \mathrm{~mm}$, thickness $=2.5 \mathrm{~mm}$ ), uniaxially pressed at $15 \mathrm{kpsi}$ and subsequently isopressed at 30 kpsi, were sintered under identical conditions. The microstructure of polished cross sections of sintered bulk samples as well as free-standing and constrained thick film elements was analyzed using scanning electron microscopy.

Electrical properties of the PNZT elements were characterized using metallized free-standing films. Square electrodes (top: 2 $\mathrm{mm} \times 2 \mathrm{~mm}$, bottom $4 \mathrm{~mm} \times 4 \mathrm{~mm}$ ) were deposited on the films using sputter deposition, where a $200 \AA$ chromium layer was deposited first, followed by a $1000 \AA$ gold layer. Capacitance and dissipation measurements were performed as a function of frequency $(1 \mathrm{kHz}-1 \mathrm{MHz})$ using an impedance analyzer (Precision LCR meter, Model 4194A, Hewlet-Packard, Palo Alto, CA).

\section{Results and Discussion}

\section{(1) Rheological Properties}

The apparent viscosity $\left(\eta_{\text {app }}\right)$ as a function of shear rate $(\dot{\gamma})$ for PNZT suspensions $\left(\phi_{\mathrm{PNZT}}=0.10\right)$ with varying Menhaden fish oil (MFO) concentration (weight percent relative to powder mass) is shown in Fig. 1. The accompanying inset plot in Fig. 1 depicts 


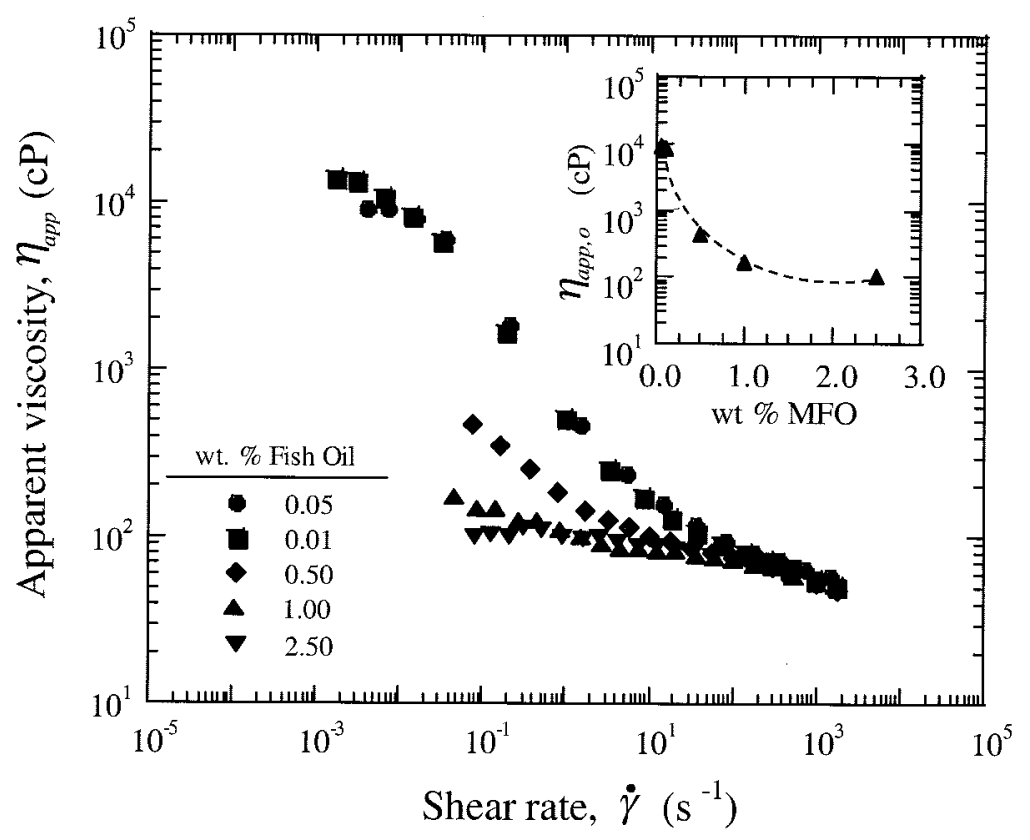

Fig. 1. $\log -\log$ plot of apparent viscosity $\left(\eta_{\text {app }}\right)$ as a function of shear rate $(\dot{\gamma})$ for PNZT suspensions $\left(\phi_{\text {PNZT }}=0.10\right)$ with varying Menhaden fish oil $($ MFO) concentrations (weight percent dispersant relative to powder mass). Inset plot depicts the low shear apparent viscosity ( $\eta_{\text {app }, 0}$ ) as a function of MFO.

the low shear apparent viscosity $\left(\eta_{\mathrm{app}, 0}\right)$, defined as the apparent viscosity at the lowest shear rate measured, as a function of dispersant concentration. The $\eta_{a p p, 0}$ and the degree of shear thinning decreased with increasing dispersant concentration, indicative of enhanced suspension stability. Suspensions containing dispersant concentrations of $1.0 \mathrm{wt} \%$ or higher were most stable, exhibiting nearly Newtonian behavior. The optimal dispersant content was identified as the concentration yielding the minimum low shear apparent viscosity, i.e., $1.0 \mathrm{wt} \%$ MFO for PNZT suspensions $\left(\phi_{\mathrm{PNZT}}=0.10\right)$ in $\alpha$-terpineol.

Similar rheological measurements were conducted to determine the effectiveness of the other dispersants evaluated: (1) oleic acid, (2) Emphos 21-A, and (3) Hypermer PS-3. In each case, the apparent suspension viscosity $\left(\eta_{\text {app }}\right)$ as a function of shear rate $(\dot{\gamma})$ was measured for varying dispersant concentration, and the optimal concentration for each dispersant was identified. Their relative effectiveness is illustrated in Fig. 2, where $\eta_{\text {app }}$ is plotted as a function of shear rate for suspensions formulated with optimal dispersant concentration. Note that suspensions dispersed using Hypermer PS-3 or MFO exhibited the lowest apparent viscosities and degree of shear thinning, suggesting that these dispersants provided the most effective stabilization of the PNZT particles. Because of difficulties associated with dissolving Hypermer PS-3 in concentrated suspensions, Menhaden fish oil was chosen for additional experiments.

The apparent solution viscosity $\left(\eta_{\text {app }}^{\text {soln }}\right.$ ) as a function of shear rate $(\dot{\gamma})$ for polymer solutions of varying ethyl cellulose volume fraction $\left(\phi_{\mathrm{EC}}^{\text {soln }}\right)$ is shown in Fig. 3(a). Newtonian behavior was observed over the range of ethyl cellulose concentrations studied $\left(\phi_{\mathrm{EC}}^{\text {soln }}=0-0.05\right) . \eta_{\mathrm{app}}^{\text {soln }}$ increased exponentially with $\phi_{\mathrm{EC}}^{\text {soln }}$, as shown in Fig. 3(b). The dramatic rise in solution viscosity stems from the molecular architecture of such cellulosic binders. These species occupy a large excluded volume in solution due to their inflexible backbone structure, which consists of rigid ether bonds $(\mathrm{C}-\mathrm{O}-\mathrm{C})$ that provide the link between monomer units. ${ }^{15,27,29}$

The relative viscosity $\left(\eta_{\text {rel }}\right)$ as a function of solids volume fraction $\left(\phi_{\mathrm{PNZT}}\right)$ for PNZT suspensions prepared from as-received and dispersant-coated, attrition-milled PNZT powders is plotted in Fig. 4. The relative viscosity increased with increasing solids volume fraction in both cases; however, suspensions prepared from as-received powders exhibited significantly higher relative viscosity at a given solids volume fraction when compared with the dispersant-coated, attrition-milled case. Such behavior likely results from agglomerates present in the as-received powders, resulting in a greater effective solids volume fraction due to entrapped solvent and hence increased viscosity. The maximum working solids volume fraction $\left(\phi_{\mathrm{m}}\right)$ for each case was estimated from the data plotted in Fig. 4 by extrapolating to high relative viscosity $\left(\eta_{\text {rel }}=70\right)$. The estimated $\phi_{\mathrm{m}}$ for the as-received and dispersant-coated suspensions was 0.38 and 0.43 , respectively.

The appropriate vehicle composition for producing pastes $\left(\phi_{\text {PNZT }}=0.35\right)$ with viscosities of $10^{4}-10^{5} \mathrm{cP}$ was estimated using the Krieger-Dougherty ${ }^{30}$ relation given by

$$
\frac{\eta_{p}}{\eta_{v}}=\left(1-\frac{\phi_{s}}{\phi_{m}}\right)^{-K_{H} \phi_{m}}
$$

where $\eta_{\mathrm{p}}$ is the paste viscosity, $\eta_{\mathrm{v}}$ is the vehicle viscosity, $\phi_{\mathrm{s}}$ is the solids volume fraction $\left(\phi_{\mathrm{s}}=\phi_{\mathrm{PNZT}}\right), \phi_{\mathrm{m}}$ is the maximum packing

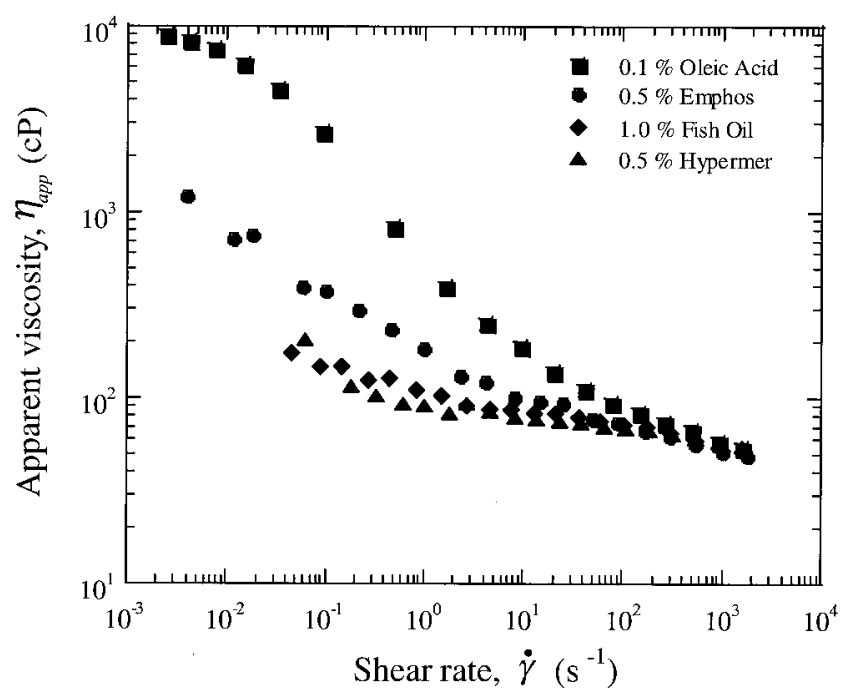

Fig. 2. $\log -\log$ plot of apparent viscosity $\left(\eta_{\text {app }}\right)$ as a function of shear rate $(\dot{\gamma})$ for PNZT suspensions $\left(\phi_{\mathrm{PNZT}}=0.10\right)$ with varying concentrations (weight percent relative to powder mass) of Menhaden fish oil (MFO), oleic acid, Emphos 21-A, and Hypermer PS-3 dispersants. 

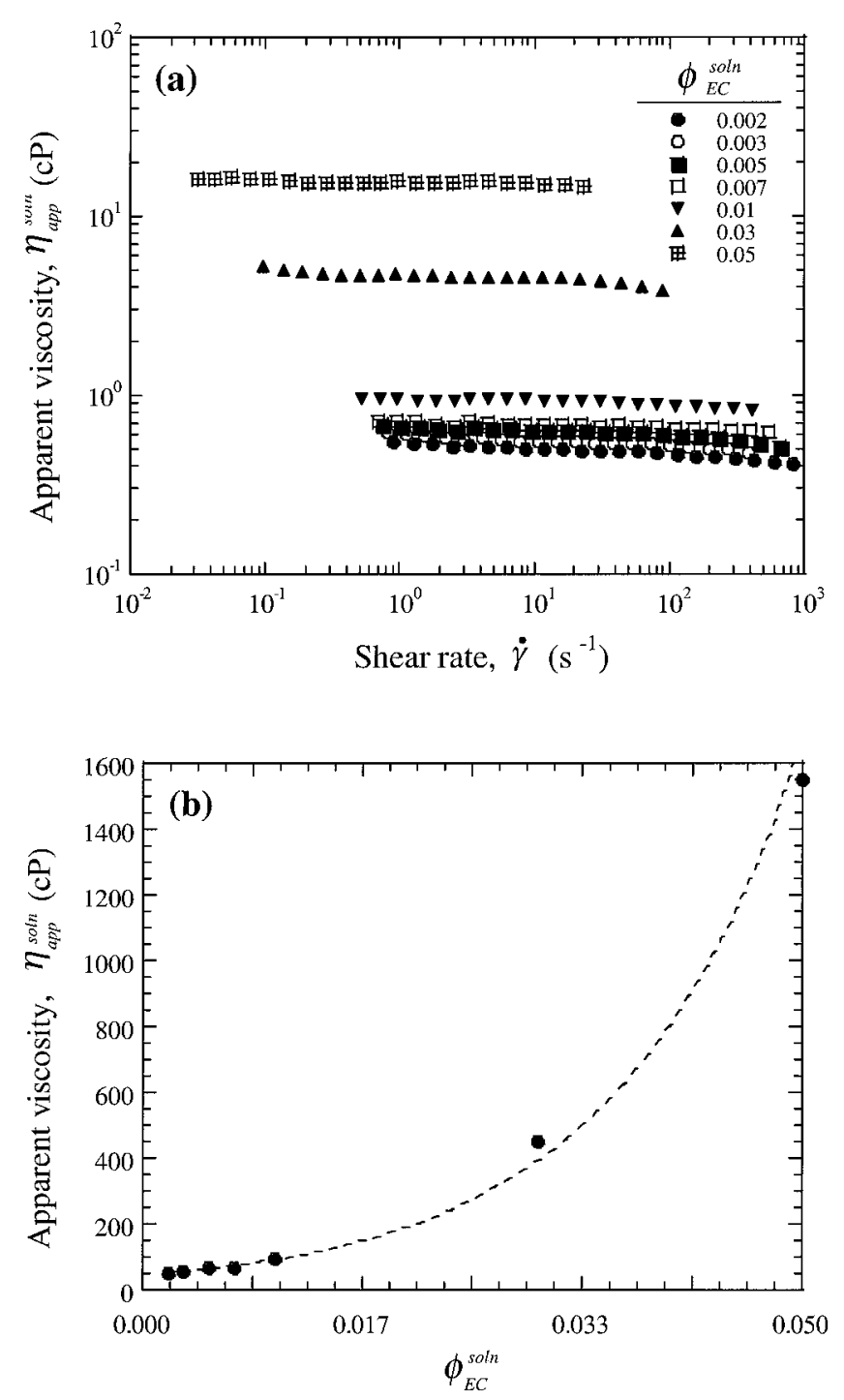

Fig. 3. (a) $\log -\log$ plot of the apparent solution viscosity $\left(\eta_{\text {app }}^{\text {soln }}\right)$ as a function of shear rate $(\dot{\gamma})$ for $\alpha$-terpineol solutions containing varying amounts of ethyl cellulose, and (b) plot of the apparent solution viscosity $\left(\eta_{\text {app }}^{\text {soln }}\right)$ as a function of ethyl cellulose volume fraction $\left(\phi_{\mathrm{EC}}^{\text {soln }}\right)$.

fraction, and $K_{\mathrm{H}}$ is the apparent hydrodynamic shape factor of particles. Here, the estimated values of the maximum solids volume fraction $\left(\phi_{\mathrm{m}}\right)$ were used with $K_{\mathrm{H}}=3.5$ for these nonspherical particles. Based on these calculations, vehicle viscosities in the range $350-8000 \mathrm{cP}$ are necessary, corresponding to ethyl cellulose volume fractions of $0.03-0.07$, as estimated from the plot of $\eta_{\mathrm{app}}^{\mathrm{soln}}$ as a function of $\phi_{\mathrm{EC}}^{\text {soln }}($ Fig. 3(b)). Therefore, PNZT pastes $\left(\phi_{\mathrm{PNZT}}=0.35\right)$ were formulated with $\phi_{\mathrm{EC}}^{\text {soln }}=0.05$ which yields $\eta_{\mathrm{app}}^{\text {soln }}=1575 \mathrm{cP}$.

The apparent viscosity as a function of shear rate for representative PNZT pastes $\left(\phi_{\mathrm{PNZT}}=0.35, \phi_{\mathrm{EC}}^{\text {soln }}=0.05\right)$ at varying aging times is shown in Figs. 5(a) and (b) for as-received and dispersantcoated PNZT powders, respectively. Both pastes exhibited pseudoplastic behavior; however, significant differences in their aging behavior were observed. Pastes prepared from as-received powders showed a substantial decrease in the degree of shear thinning and the low shear apparent viscosity with time, as illustrated in the inset plot of Fig. 5(a), where $\eta_{\text {app }, 0}$ is plotted as a function of aging time. $\eta_{\text {app }, 0}$ decreased from $9.5 \times 10^{5} \mathrm{cP}$ for unaged (as-milled) pastes to $\sim 2.0 \times 10^{5} \mathrm{cP}$ after 50 days, suggesting an improvement in paste stability with time. In pastes prepared from dispersant coated particles, the apparent viscosity decreases from $3 \times 10^{6}$ to $7 \times 10^{5} \mathrm{cP}$ after 1 day of aging. On further aging (up to 50 days), little change in the rheological behavior of the paste was observed.

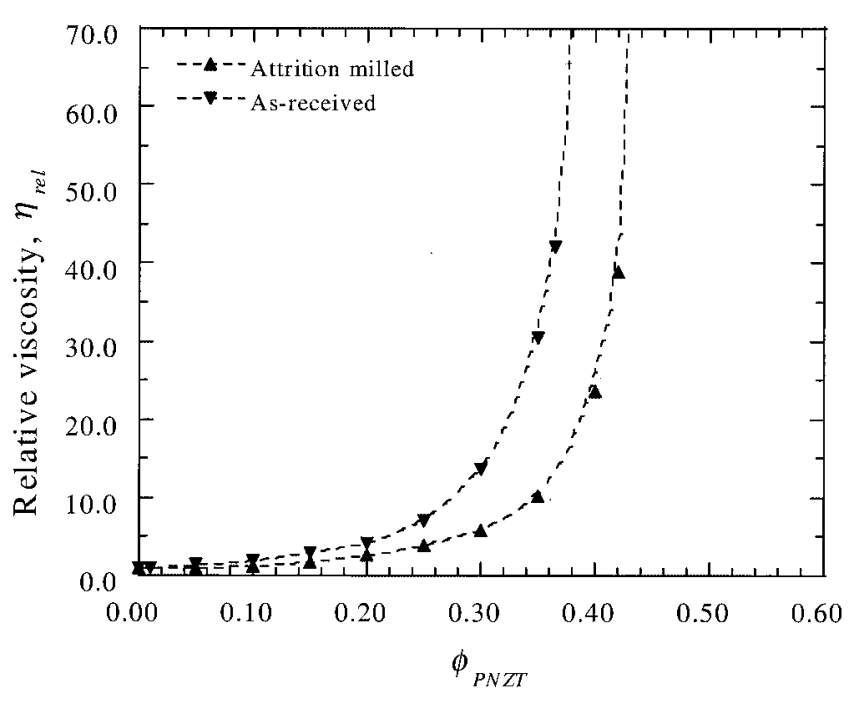

Fig. 4. Plot of the relative viscosity $\left(\eta_{\text {rel }}\right)$ as a function of volume fraction $\left(\phi_{\mathrm{PNZT}}\right)$ for PNZT suspensions prepared from as-received and attrition milled powders; estimated maximum working solids volume fraction for the as-received and attrition-milled powders were 0.38 and 0.43 , respectively.

These observations suggest that aging phenomena in pastes prepared from as-received powders results from slow diffusion of dispersant molecules to the particle surface in the high-viscosity vehicles utilized, thereby retarding dispersant adsorption and, hence, particle stabilization. ${ }^{31}$ In related work, Tohver et al. ${ }^{23}$ studied the aging behavior of $\mathrm{ZnO}$ varistor thick film pastes and found that the low shear apparent viscosity of samples stored at elevated temperatures $\left(40^{\circ}-50^{\circ} \mathrm{C}\right)$ decreased to its steady state value more rapidly than samples aged equivalent times at room temperature $\left(22^{\circ} \mathrm{C}\right)$. Such behavior suggests that the kinetics of dispersant diffusion/adsorption may be accelerated by heating, thereby reducing the aging time required to achieve steady-state rheological behavior.

\section{(2) Surface Morphology of Printed Elements}

The impact of paste rheology on the leveling behavior and surface topography of printed components was probed using laser profilometry. The cross-sectional profile as a function of leveling time for a single line print of PNZT paste prepared from dispersant-coated, attrition-milled powder after 50 days of aging is plotted in Fig. 6. The dimensional changes observed are plotted in Fig. 7 as line width and height as a function of leveling time. Line broadening of $5 \%-6 \%$ occurred after $\sim 400 \mathrm{~s}$, with no further measurable change up to $22 \mathrm{~min}$. A corresponding decrease in the bead height of $1 \%-2 \%$ was measured after $400 \mathrm{~s}$; however, longer leveling times showed additional decreases in bead height of up to $10 \%$ after $22 \mathrm{~min}$, suggesting that some solvent evaporation occurs.

As-dried PNZT films were characterized using laser profilometry to determine thickness uniformity. Figure 8 shows height plotted as a function of length $(X)$ for a representative dried, two-layer film scanned perpendicular to the printing direction. Residual flow during settling (leveling) reduced surface roughness; however, scalloped features resulting from the serpentine print pattern were still observed. Representative films had an average film thickness of $61.6 \pm 3.2 \mu \mathrm{m}$. It is expected that such scalloping effects may be reduced by fine-tuning printing conditions (i.e., increased leveling times or reduced pen tip size) or by further tailoring paste rheology. Despite moderate edge broadening effects, the desired pattern characteristics (i.e., relatively smooth surface topography and uniform thickness) were achieved. 

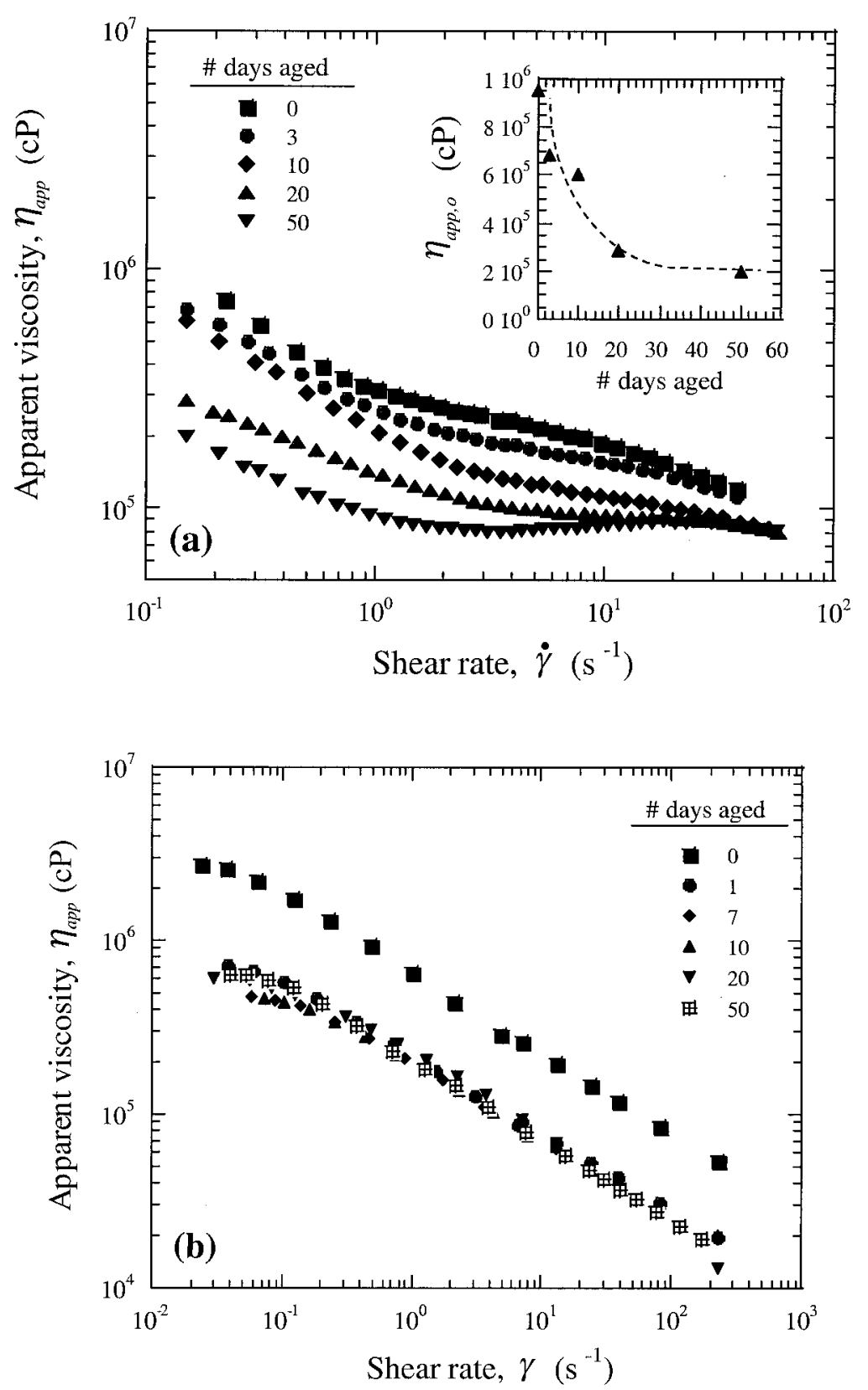

Fig. 5. $\log -\log$ plot of the apparent viscosity $\left(\eta_{\text {app }}\right)$ as a function of shear rate $(\dot{\gamma})$ at varying aging times (number of days aged) for PNZT paste $\left(\phi_{\mathrm{PNZT}}=\right.$ $0.35, \phi_{\mathrm{EC}}^{\text {soln }}=0.05$ ) prepared from (a) as-received powder, and (b) dispersant-coated, attrition-milled powder. Inset plot in (a) depicts the low shear apparent viscosity $\left(\eta_{\text {app }}^{\text {soln }}\right)$ as a function of number of days aged.

\section{(3) Microstructure Evolution and Electrical Properties of Sintered Elements}

The microstructural development of micropen printed PNZT thick films with average green densities $\left(\rho_{\mathrm{avg}}^{\mathrm{g}}\right)$ of $3.7-3.8 \mathrm{~g} / \mathrm{cm}^{3}$ $(\approx 47 \%$ theoretical) was analyzed via scanning electron microscopy (SEM). SEM photomicrographs of polished cross sections of printed elements sintered to varying maximum temperatures between $950^{\circ}$ and $1050^{\circ} \mathrm{C}$ for $5 \mathrm{~h}$ are shown in Figs. 9(a-c). For comparison, the microstructure of a representative bulk sample sintered under similar conditions is shown in Fig. 9(d). All printed PNZT layers have a high degree of intergranular porosity with small, interconnected grains, whose size increases with sintering temperature. In all cases, bulk PNZT samples $\left(\rho_{\mathrm{avg}}^{\mathrm{g}}=\right.$ $4.7-4.8 \mathrm{~g} / \mathrm{cm}^{3} ; \approx 60 \%$ theoretical) sintered to higher density $\left(6.89-7.02 \mathrm{~g} / \mathrm{cm}^{3}\right)$ than printed elements fired at the same temperature under identical conditions. The reduced sintered densities observed for printed thick film elements likely stem from both lower green density and constrained sintering effects. ${ }^{30}$ Additional experiments are being conducted to characterize the effects of green density and constrained sintering on densification of films printed from PNZT pastes prepared using as-received and attrition-milled powders.

The dependence of dielectric constant $(K)$ on frequency is shown in Fig. 10(a) for PNZT thick film devices sintered at varying maximum temperatures. A modest dependence of $K$ on frequency was observed, with the dielectric constant decreasing less than $20 \%$ over 6 orders of magnitude in frequency. Dielectric constants ranged from 1265 to 1570 depending on frequency and sintering temperature, where the highest value of 1570 was measured at $1 \mathrm{kHz}$ for samples sintered at $1050^{\circ} \mathrm{C}$ for $5 \mathrm{~h}$. The dielectric constant $(K)$ at constant frequency of micropen printed components increased with increasing sintering temperature as a result of higher film density. ${ }^{34,35}$ These results compare favorably with related screen-printed ${ }^{33,34-37}$ and tape-cast thick film devices. ${ }^{1-3}$ 


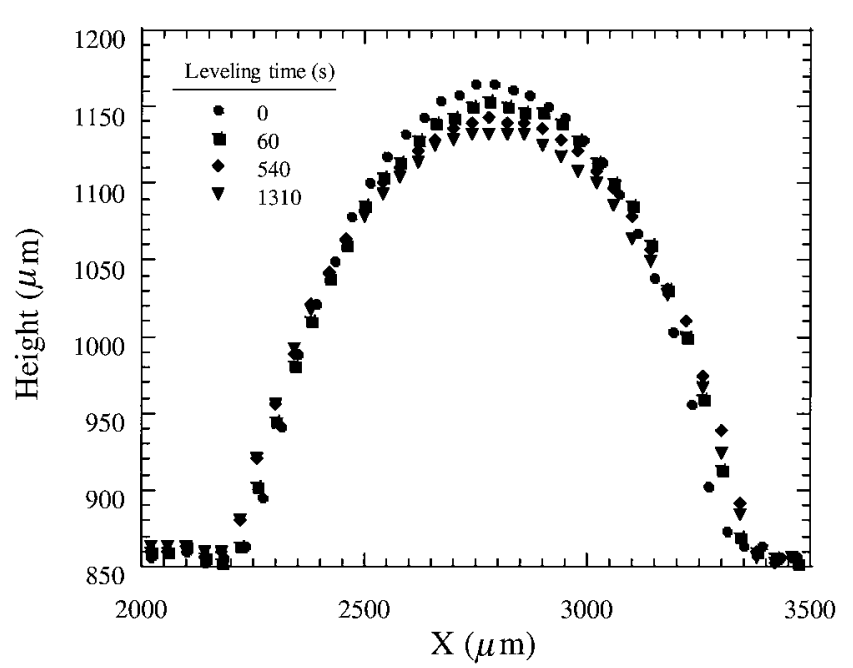

Fig. 6. Plot of the cross-sectional height as a function of leveling time for a single line print of PNZT paste prepared from dispersant-coated, attrition-milled powder after 50 days of aging.

The corresponding dissipation factors $(D)$ as a function of frequency for PNZT thick film devices sintered at varying maximum temperatures are plotted in Fig. 10(b). A significant frequency dependence of the dissipation factor was observed, where values of less than $4.5 \%$ were measured at all frequencies. For comparison, polished bulk samples fired at $1000-1050^{\circ} \mathrm{C}$ displayed $K$ of $1011-1051$ and tan $\delta$ from 0.036 to 0.022 . The reduction in $K$ of bulk samples is attributed to the higher density of bulk components, whereas greater loss tangents $(>0.04)$ observed in micropen printed samples fired at $1050^{\circ} \mathrm{C}$ are attributed to increased lead loss during firing resulting from the comparatively higher surface area/volume ratios. ${ }^{8,28,32}$ Note, weight losses between 2 and 3 wt $\%$ were measured for samples sintered above $1000^{\circ} \mathrm{C}$. The dissipation factors of these micropen printed PNZT layers are $\sim 1 \%-3 \%$ higher than those reported for related screen printed PZT 53/47 thick films. ${ }^{34,35}$

\section{Summary}

PNZT thick film pastes with tailored rheological behavior for direct-write fabrication of capacitor elements have been developed. Paste formulations were optimized with respect to the type

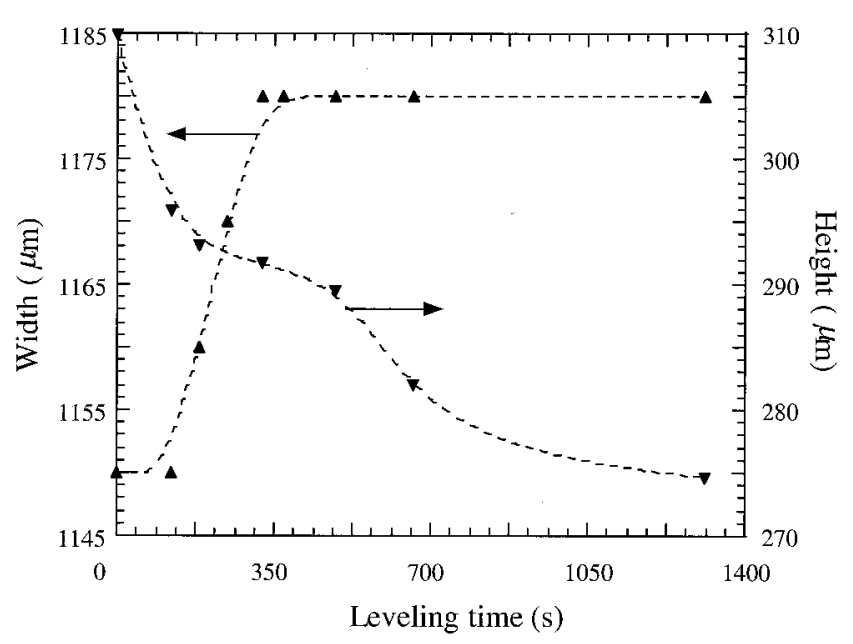

Fig. 7. Plot of the cross-sectional width and height as a function of leveling time for a single line print of PNZT paste prepared from dispersant-coated, attrition-milled powder after 50 days of aging.

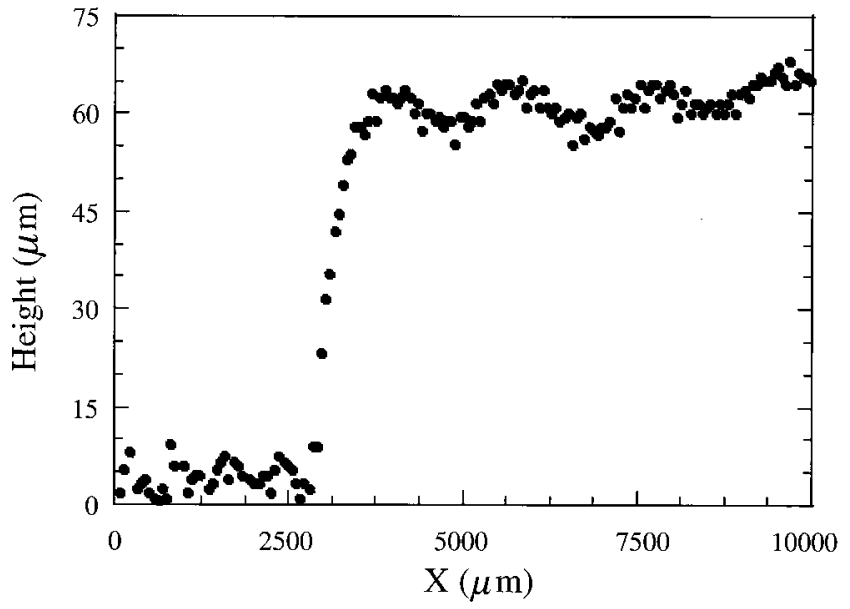

Fig. 8. Plot of height as a function of length $(X)$ for representative dried, two layer PNZT films printed from paste prepared using dispersant-coated, attrition-milled powder after 50 days of aging $\left(\phi_{\mathrm{PNZT}}=0.35, \phi_{\mathrm{EC}}^{\text {soln }}=\right.$ $0.05)$; scan is perpendicular to the printing direction.

of dispersant and its concentration, solids volume fraction, and vehicle composition. The pastes exhibited pseudoplastic rheological behavior with apparent viscosities of $\sim 5 \times 10^{4} \mathrm{cP}$ in the settling shear rate range, resulting in printed elements with relatively smooth surface topographies and uniform thickness $(<5 \%$ deviation from average height). Aging phenomena were related to adsorption kinetics of the dispersant, where pastes prepared from as-received powders exhibited significant aging (i.e., a reduction in low shear viscosity and the degree of shear thinning as a function of time). In contrast, pastes prepared from dispersant-coated powders were stable and showed no significant rheological changes after 1 day of aging, suggesting excellent storage stability and thus, extended shelf life. Capacitor components prepared from such pastes exhibited high dielectric constants $(>1200)$ with a modest frequency dependence and dissipation factors below $4.5 \%$.

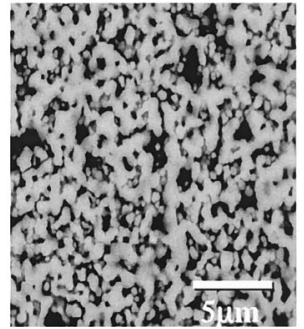

(a)

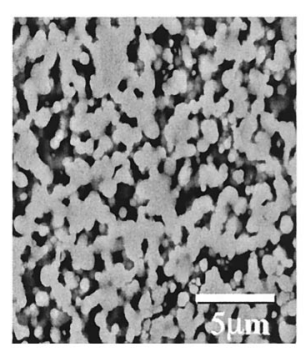

(c)

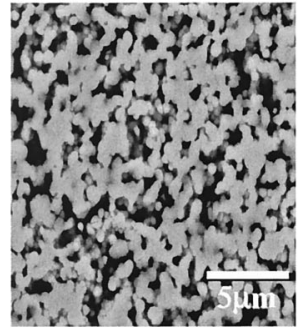

(b)

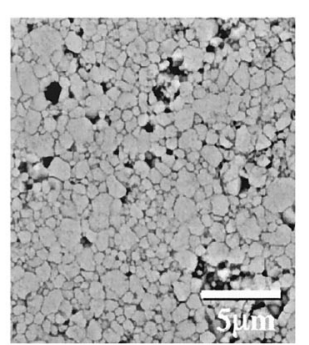

(d)
Fig. 9. Scanning electron micrographs of polished cross sections of micropen printed, free-standing PNZT elements sintered to varying maximum temperatures: (a) $950^{\circ} \mathrm{C} / 5 \mathrm{~h}$, (b) $1000^{\circ} \mathrm{C} / 5 \mathrm{~h}$, and (c) $1050^{\circ} \mathrm{C} / 5 \mathrm{~h}$. A bulk sample sintered at $1050^{\circ} \mathrm{C} / 3 \mathrm{~h}$ is shown for comparison in (d). 

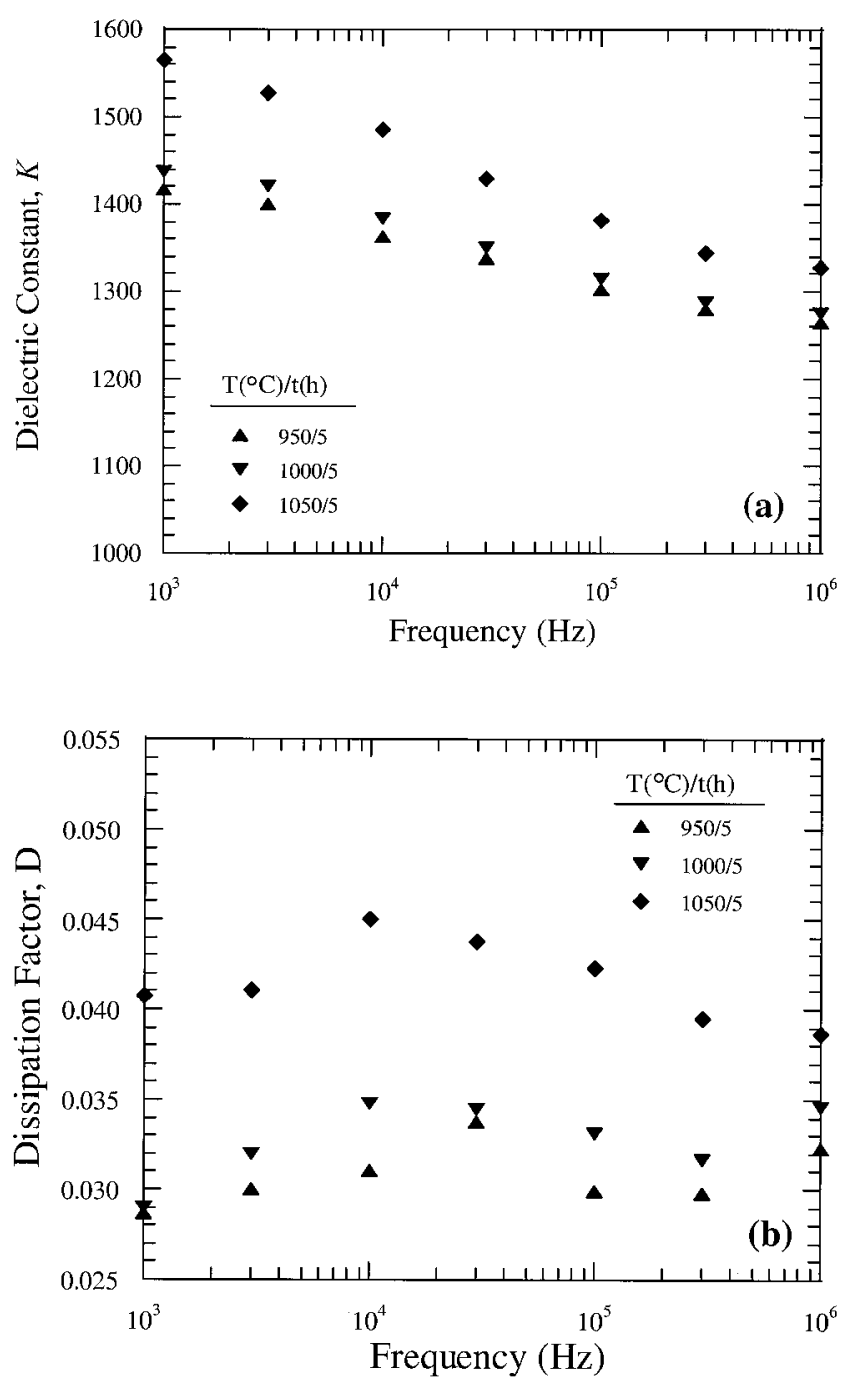

Fig. 10. Semilog plot of the (a) dielectric constant $(K)$ and (b) dissipation factor $(D)$ as a function of frequency for PNZT devices sintered at varying maximum temperature and soak time.

\section{Acknowledgments}

We thank Chip Olson for experimental assistance, Diana Sipola and Jim Voigt for supplying PNZT powders used in this study, and Bruce Tuttle for useful discussions.

\section{References}

${ }^{1}$ R. E. Mistler, "Tape Casting: The Basic Process for Meeting the Needs of the Electronics Industry," Am. Ceram. Soc. Bull., 69 [6] 1022-26 (1990).

${ }^{2}$ E. P. Hyatt, "Making Thin, Flat Ceramics-A Review," Am. Ceram. Soc. Bull., 65 [4] 637-38 (1986).

${ }^{3}$ G. N. Howatt, R. G. Breckenridge, and J. M. Brownlow, "Fabrication of Thin Ceramic Sheets for Capacitors," J. Am. Ceram. Soc., 30 [8] 237-42 (1947).

${ }^{4}$ G. de Cicco, B. Morten, and M. Prudenziati, Advanced Thick Film Sensors, Proceedings of the 1st Italian Conference on Sensors and Microsystems (Rome, Italy). World Scientific, Singapore, 1996.

${ }^{5}$ R. D. Jones, Hybrid Circuit Design and Manufacture. Marcel Dekker, New York, 1982.

${ }^{6}$ G. E. Pike and C. H. Seager, "Electrical Properties and Conduction Mechanisms of Ru-Based Thick Film (Cermet) Resistors," J. Appl. Phys., 48 [12] 5152-69 (1977).

${ }^{7}$ J. E. Sergent and C. A. Harper, "Thick Film Materials and Processes"; pp. 3/103-3/149 in Hybrid Microelectronic Handbook. Edited by J. E. Sergent and C. A. Harper. McGraw-Hill, New York, 1995.
${ }^{8}$ V. Tajan, P. Gonnard, and M. Troccaz, "Elaboration of PZT Thick Films by Screen Printing," Proc. SPIE-Int. Soc. Opt. Eng., 2779, 564-69 (1996).

${ }^{9}$ D. Dimos and P. Yang, "Direct-Write Fabrication of Integrated, Multilayer Ceramic Components"; pp. 225-27 in Proceedings of the Solid Freeform Fabrication Symposium (Austin, TX). University of Texas, Austin, TX, 1997.

${ }^{10}$ D. Dimos, B. H. King, and P. Yang, "Direct-Write Fabrication of Integrated, Multilayer Passive Components"; pp. 186-90 in Proceedings of the International Symposium on Advanced Packaging Materials-Processes, Properties and Interfaces (IEEE Cat. No. 99TH8405). International Microelectronics and Packaging Society, Reston, VA, 1999.

${ }^{11}$ B. King, S. Morissette, and P. Yang, "Influence of Rheology on Deposition Behavior of Ceramic Pastes in Direct Fabrication Systems"; in Proceedings of the Solid Freeform Fabrication Symposium (Austin, TX). University of Texas, Austin, TX, 1998.

${ }^{12}$ J. C. Lin and C. Y. Wang, "Effect of Surfactant Treatment of Silver Powder on the Rheology of Its Thick-film Paste," Mater. Chem. Phys., 45, 136-44 (1996).

${ }^{13}$ T. E. Karis, "An Overview of Rheology in the Computer Industry," J. Appl. Polym. Sci., 59, 1405-16 (1996).

${ }^{14} \mathrm{G}$. Moeller-Johnson, "The Importance of Rheology in Screen-Printing Ink: Newtonian vs. Shear Thinning," ISHM Proc., 320-37 (1987).

${ }^{15}$ R. M. Stanton, "Rheological Aspects of Thick Film Technology: An Investigation of the Flow Properties of Ethyl Cellulose Vehicle System," Int. J. Hybrid Microelectron., 6 [1] 419-32 (1983).

${ }^{16}$ R. E. Trease and R. L. Dietz, "Rheology of Pastes in Thick-film Printing," Solid State Technol., [Jan.] 39-43 (1972).

${ }^{17}$ S. F. Wang and J. P. Dougherty, "Silver-Palladium Thick-Film Conductors," J. Am. Ceram. Soc., 77 [12] 3051-72 (1994).

${ }^{18}$ R. W. Vest, "Materials Science of Thick Film Technology," Am. Ceram. Soc. Bull., 65 [4] 631-36 (1986).

${ }^{19}$ R. R. Tummala, "Ceramic and Glass-Ceramic Packaging in the 1990's," J. Am. Ceram. Soc., 74 [5] 895-908 (1991).

${ }^{20}$ R. DellAcqua, "Non-conventional Applications of Thick Film Technology," Hybrid Circuits, 12, 10-21 (1987).

${ }^{21}$ G. V. Planer and L. S. Phillips, "Printing Procedures"; pp. 80-82 in Thick Film Circuits. Crane, Russak and Co., New York., 1972.

${ }^{22}$ L. F. Miller, "Screenability and Rheology," Solid State Technol., [Oct.] 54-60 (1974).

${ }^{23}$ V. Tohver, J. Lewis, B. A. Tuttle, and D. B. Dimos, unpublished work, 1998.

${ }^{24}$ B. Morosin, A. C. Lawson, G. H. Kwei, J. A. Voigt, and B. A. Tuttle, "Neutron Diffraction Studies on Recrystallization of Solution Derived Lead Zirconate Titanates"; pp. 609-14 in Neutron Scattering in Materials Science II (Symposium, Boston, MA, November 28 to December 1, 1994). Edited by D. A. Neumann, T. P. Russell, and B. J. Wuensch. Materials Research Society, Pittsburgh, PA, 1995.

${ }^{25}$ C. Moure, M. Villegas, J. F. Fernandez, and P. Duran, "Microstructural and Piezoelectric Properties of Fine Grained PZT Ceramics Doped with Donor and/or Acceptor Cations," Ferroelectrics, 127 [1-4] 113-18 (1992).

${ }^{26}$ A. Schonecker, H.-J. Gesemann, and L. Seffner, "Low-Sintering PZT-Ceramics for Advanced Actuators"; in ISAF '96 Proceedings of the 10th IEEE International Symposium on Applications of Ferroelectrics (East Brunswick, NJ). Institute of Electrical and Electronics Engineers, New York, 1996.

${ }^{27}$ Dow Chemicals Inc., "Ethocel: Ethyl Cellulose," 1997.

${ }^{28}$ A. I. Kingon and J. B. Clark, "Sintering of PZT Ceramics: I. Atmosphere Control," J. Am. Ceram. Soc., 66 [4] 253-56 (1981).

${ }^{29}$ G. S. Rekhi and S. S. Jambhekar, "Ethylcellulose-A Polymr Review," Drug Dev. Ind. Pharm., 21 [1] 61-77 (1995).

${ }^{30} \mathrm{~J}$. A. Reed, Introduction to the Principles of Ceramic Processing. WileyInterscience, New York, 1988.

${ }^{31}$ L. Xiong, C. Yongjie, et al., "A Study of the Mechanism of Adsorption of Ethyl Cellulose on Silver Powders," J. Therm. Anal., 49, 1357-64 (1997).

${ }^{32}$ A. Kingon and J. B. Clark, "Sintering of PZT Ceramics: II, Effect of PbO Content on Densification Kinetics," J. Am. Ceram. Soc., 66 [4] 256-60 (1983).

${ }^{33}$ L. Seffner and H. J. Gesemann, "Preparation and Application of PZT Thick Films"; pp. 317-20 in Electroceramics IV, Vol. 1. Verlag der Augustinus Buchhandlung, Aachen, Germany, 1994.

${ }^{34}$ J. F. Fernandez, E. Nieto, C. Moure, and P. Duran, "Processing of Porous and Dense PZT Thick Films on $\mathrm{Al}_{2} \mathrm{O}_{3}$ Substrates"; pp. 49-52 in ISAF '94 Proceedings of the Ninth IEEE International Symposium on Applications of Ferroelectrics (Cat. No. 94CH3416-5). Institute of Electrical and Electronics Engineers, New York, 1994.

${ }^{35}$ J. F. Fernandez, E. Nieto, C. Moure, P. Duran, and R. E. Newnham, "Processing and Microstructure of Porous and Dense PZT Thick Films on $\mathrm{Al}_{2} \mathrm{O}_{3}$," J. Mater. Sci., 30 [21] 5399-404 (1995).

${ }^{36}$ E. Nieto, J. F. Fernandez, C. Moure, and P. Duran, "Multilayer Piezoelectric Devices Based on PZT," J. Mater. Sci., 7 [1] 55-60 (1996).

${ }^{37}$ T. Papakostas, N. R. Harris, S. P. Beeby, and N. M. White, "Piezoelectric Thick-Film Polymer Pastes"; pp. 461-64 in Eurosensors XII, Proceedings of the 12th European Conference on Solid-State Tranducers (Southhampton, U.K.). IOP Publishing, Bristol, U.K., 1998. 